\title{
Early Recognition and Treatment of Diabetic Kidney Disease
}

\author{
Ahmed SS ${ }^{1}$, Rizwan MASM${ }^{2}$, Khan MAM${ }^{3}$, Laila TR ${ }^{4}$, Hafez $\mathrm{MA}^{5}$
}

\begin{abstract}
Diabetic kidney disease (DKD) is a progressive condition and is an important cause of end stage renal disease (ESRD) as well as a risk factor for cardiovascular morbidity and mortality. This paper reviews various evidence based clinical guidelines, scientific papers and research studies on early detection and treatment of DKD. Microalbuminuria describes the urinary excretion of small amounts of albumin which identifies the early stage of DKD. In addition to an earliest marker of kidney damage, microalbuminuria is an established high risk factor for cardiovascular morbidity and mortality. Patients with microalbuminuria who progress to macroalbuminuria are likely to progress to ESRD. However effective treatment in the early stage of DKD reduces the risk and slows the progression of kidney damage. There is general agreement that people with diabetes should be screened regularly to detect early markers of kidney damage. People with diabetes and microalbuminuria should be treated with a multifactorial intervention approach to retard the progression of DKD. Studies have clearly demonstrated that the use of angiotensin converting enzyme inhibitors or angiotensin 2 receptor blockers with improved glycemic control, hypertension control, lipid lowering, aspirin use, smoking cessation, exercise programs and dietary intervention reduced the development of overt nephropathy and ESRD.
\end{abstract}

Key words: Diabetic kidney disease, Diabetic nephropathy, Microalbuminuria, Macroalbuminuria, End stage renal disease.

1. Corresponding Author:

Prof. Dr. Sheikh Salahuddin Ahmed

MBBS, FCPS (Internal Medicine)

Professor \& Head of the Department of Medicine

Bangladesh Institute of Health Sciences (BIHS)

125/1, Darus Salam, Mirpur-1, Dhaka 1216, Bangladesh

E mail: drsksalahahmed@yahoo.com

2. Dr. Md. Abu Saleh Mohammad Rizwan, MBBS

Bangladesh Institute of Health Sciences (BIHS)

125/1, Darus Salam, Mirpur-1, Dhaka 1216, Bangladesh

3. Dr. Md. Abdul Mahid Khan, MBBS, D Card, MRCP

Assistant Professor, Department of Cardiology

Bangladesh Institute of Health Sciences (BIHS)

125/1, Darus Salam, Mirpur-1, Dhaka 1216, Bangladesh

4. Dr. Tarafdar Runa Laila, MBBS, FCPS, MS (Obs \& Gyne)

Assistant Professor, Department of Obstetrics \& Gynecology

Bangabandhu Sheikh Mujib Medical University

Shahbag, Dhaka, Bangladesh

5. Prof. Md. Abdul Hafez, MSc (Statistics), MSc (Med Demog) Professor \& Head, Department of Biostatistics

Bangladesh University of Health Sciences (BIHS)

125/1, Darus Salam, Mirpur-1, Dhaka 1216, Bangladesh

\section{Introduction}

Diabetes mellitus (DM) has been found to be the leading cause of ESRD in the developed countries like United States (US), Europe and Australia ${ }^{1-5}$. DKD occurs in $20-40 \%$ of patients with diabetes ${ }^{6}$. In Bangladesh, there is no national data on the prevalence of kidney disease in people with diabetes. Microalbuminuria is the earliest marker of DKD and a risk factor for the development of cardiovascular morbidity and mortality ${ }^{7-10}$. The prevalence of microalbuminuria in patients with diabetes is $10-30 \%{ }^{11}$. DKD is a progressive condition; patients with microalbuminuria who progress to macroalbuminuria represents a more severe and established form of renal disease, are likely to progress to ESRD, and are more predictive of cardiovascular mortality and morbidity than microalbuminuria ${ }^{2,12}$. Patients who progress to ESRD require renal replacement therapy (RRT) to sustain life. RRT includes maintenance dialysis and kidney transplantation. But most of the people in our country are not able to afford the treatment cost as dialysis or kidney transplantation is very expensive and facilities of such treatment are not widely available. However, there is strong evidence that a number of interventions if initiated at early stage of DKD reduce the risk and slow the progression of kidney damage ${ }^{6}$. Therefore the two main purposes of early detection and treatment of DKD are (i) to prevent progression to ESRD and (ii) to prevent cardiovascular morbidity and mortality.

\section{Diabetic Kidney Disease}

The term DKD refers to kidney disease caused by diabetes ${ }^{13}$. DKD is usually diagnosed on the basis of a raised urine albumin or a reduced glomerular filtration rate or GFR $(<$ $60 \mathrm{ml} / \mathrm{min} / 1.73 \mathrm{~m} 2$ ) persisting for 3 months or more ${ }^{2,13}$. Traditionally termed "diabetic nephropathy," is a clinical diagnosis that historically has been based on the findings of albuminuria with no other cause, in a person with diabetes ${ }^{13}$. The term diabetic glomerulopathy is reserved for biopsy-proven kidney disease caused by diabetes ${ }^{13}$. In most individuals the diagnosis of DKD is made clinically, as biopsy may not alter management of such patient. However a kidney biopsy may be required in some patients with diabetes and chronic kidney disease (CKD) to determine the underlying cause; and referral to a physician experienced in the care of kidney disease should be considered when there is uncertainty about the etiology of kidney disease (patients having heavy proteinuria, hematuria, active urine sediment, absence of retinopathy, rapid decline in GFR, resistant hypertension $)^{6}$.

The criteria for diagnosis of DKD vary somewhat between different guidelines. Most of the clinical guidelines consider microalbuminuria as the earliest stage of $\mathrm{DKD}^{6-}$ 9,14. American Diabetic Association (ADA) has considered microalbuminuria as the earliest clinical evidence of DKD, and patients with microalbuminuria are referred to as having incipient nephropathy ${ }^{1}$. The term overt nephropathy has been used to those diabetic patients having macroalbuminuria. Scottish intercollegiate guidelines network (SIGN) classify $\mathrm{DKD}$, on the basis of the extent of urine protein excretion, as either microalbuminuria or nephropathy (having 
macroalbuminuria) ${ }^{8}$. National Kidney Foundation (NKF), an organization in the US, considers CKD attributable to DKD in the presence of (1) macroalbuminuria or microalbuminuria plus retinopathy, and (2) in people with type 1 diabetes, in the presence of microalbuminuria plus duration of diabetes longer than 10 years ${ }^{13}$.

\section{Microalbuminuria and Macroalbuminuria}

NKF, defines microalbuminuria as excretion of $30-300 \mathrm{mg}$ of albumin in a 24 hour urine collection sample \{equivalent to albumin excretion rate (AER) of $20-200 \mu \mathrm{g} / \mathrm{min}$ in a timed collection of urine; or albumin creatinine ratio (ACR) 30$300 \mathrm{mg} / \mathrm{g}$ without regard to age \& sex in a random or spot sample of urine $\}$, with values $>300 \mathrm{mg} / 24$ hour being defined as macroalbuminuria ${ }^{13}$. Macroalbuminuria is also known as clinical albuminuria or proteinuria (as it correlates with a urinary protein excretion $0.5 \mathrm{~g} / 24$ hour) ${ }^{1,15}$.

Cut-off values and units of measurement for microalbuminuria differ somewhat among various clinical guidelines. ADA has defined microalbuminuria as excretion of 30-299 $\mathrm{mg}$ of albumin in a 24 hour urine collection (equivalent to albumin excretion rate of $20-199 \mu \mathrm{g} / \mathrm{min}$ in a timed collection of urine; or ACR 30-299 $\mu \mathrm{g} / \mathrm{mg}$ creatinine in a random or spot sample of urine irrespective of sex), with values $\geq 300 \mathrm{mg} / 24$ hour being defined as macroalbuminuria ${ }^{1}$. Microalbuminuria has been defined as 2.5-30.0 mg/ mmol (men) and 3.5$30.0 \mathrm{mg} / \mathrm{mmol}$ (women) in Europe ${ }^{8,15,16}, 2.0-20.0 \mathrm{mg} / \mathrm{mmol}$ (men) and 2.8-28.0 (women) in $\mathrm{Canada}^{17}$, and 2.5-25.0 $\mathrm{mg} / \mathrm{mmol}$ (men) and 3.5-35.0 (women) in Australia $^{3}$ and macroalbuminuria as $>20 / 28 \mathrm{mg} / \mathrm{mmol},>30 \mathrm{mg} / \mathrm{mmol}$ and $>25 / 35 \mathrm{mg} / \mathrm{mmol}$ respectively ${ }^{2}$. National Institute for Health and Clinical Excellence (NICE), a health organization in the United Kingdom (UK), defines microalbuminuria as ACR 2.5 to $25.0 \mathrm{mg} / \mathrm{mmol}$ in men and ACR 3.5 to $35 \mathrm{mg} /$ mmol in women ${ }^{18}$. International Diabetes Federation (IDF) considers microalbuminuria ACR $>2.5 \mathrm{mg} / \mathrm{mmol}$ in men, > $3.5 \mathrm{mg} / \mathrm{mmol}$ in women. An ACR $>30 \mathrm{mg} / \mathrm{mmol}$ indicates macroalbuminuria ${ }^{2}$.

\section{Glomerular Filtration Rate}

The GFR is the best measure of overall kidney function ${ }^{19}$. The normal level of GFR varies according to age, sex, and body size. In healthy young adult of 30 years or younger, the normal GFR is approximately $125 \mathrm{~mL} / \mathrm{min}$ per $1.73 \mathrm{~m}^{2}$ and declines by approximately $1 \mathrm{~mL} / \mathrm{min}$ per $1.73 \mathrm{~m}^{2}$ per year thereafter ${ }^{19}$. Estimation of the GFR no longer requires a 24-hour urine collection for creatinine clearance but can be accomplished with similar accuracy using mathematic formulas most commonly used are the Modification of Diet in Renal Disease (MDRD) equation and the Cockcroft-Gault equation. Many laboratories now report an estimated GFR, (eGFR), using the MDRD equation which is based on serum creatinine, age, sex and race $^{3}$. The MDRD has the advantage of being more accurate than the Cockcroft-Gault in persons with a GFR less than $90 \mathrm{~mL} /$ minute $^{19-22}$. At GFR below $60 \mathrm{~mL} /$ $\mathrm{min}$, the prevalence of complications of CKD increases ${ }^{23-25}$.

Measurement of creatinine clearance using timed (for example, 24-hour) urine collections does not improve the estimate of GFR over that provided by prediction equations. A 24-hour urine sample provides useful information for (a) estimation of GFR in individuals with exceptional dietary intake (vegetarian diet, creatine supplements) or muscle mass (amputation, malnutrition, muscle wasting), (b) assessment of diet and nutritional status and (c) need to start dialysis ${ }^{19}$.

\section{Natural History of Diabetic Kidney Disease}

The natural history of DKD is characterized by a sequence of events that was initially defined for patients with type 1 diabetes (T1DM), but appears similar in type 2 diabetes (T2DM). The typical early clinical presentation of DKD is microalbuminuria, which generally appears 5-15 years after the patient is diagnosed with $\mathrm{DM}^{14}$. This is the earliest clinical evidence of $\mathrm{DKD}$, and patients with microalbuminuria are referred to as having incipient nephropathy ${ }^{1}$. At this stage of CKD dipstick tests for proteinuria are typically negative. Without specific interventions, diabetic patients with microalbuminuria progress gradually to overt nephropathy by developing macroalbuminuria, edema and nephrotic syndrome; there is steady decline of GFR, rise of blood pressure and the pathological changes in the kidneys are likely irreversible ${ }^{1,3}$. Eventually, the characteristic clinical picture of renal failure develops. ESRD develops in 50\% of type 1 diabetic individuals with overt nephropathy within 10 years and in $>75 \%$ by 20 years ${ }^{1}$. Only $20 \%$ of type 2 diabetic patients with overt nephropathy will go on to ESRD within the next 20 years $^{26}$.

Reduction in GFR in patients with diabetes but no microalbuminuria is well described both in T1DM and T2DM ${ }^{27,28}$; kidney biopsy in such patients often shows histological evidence of $\mathrm{DKD}^{29}$. In one study it was found that up to $30 \%$ of people with T2DM who had a GFR $<60 \mathrm{ml} /$ $\mathrm{min} / 1.73 \mathrm{~m} 2$ remained normoalbuminuric ${ }^{30,31}$. Therefore, in diabetes, CKD may develop in the absence of abnormalities in urinary albumin excretion ${ }^{1-3,13}$.

\section{Screening for Diabetic Kidney Disease}

Screening for DKD should include measurement of urinary albumin for microalbuminuria. As a significant proportion of people with DM may develop CKD in the absence of albuminuria, measurement of serum creatinine and eGFR is required in addition to measurement for albuminuria ${ }^{1-3,13}$.

NKF and ADA recommends to commence initial screening at 5 years after the diagnosis of T1DM or from diagnosis of T2DM; and thereafter annually ${ }^{1,6,13}$. Microalbuminuria rarely occurs with short duration of $\mathrm{T}_{1} \mathrm{DM}^{1}$. There is currently no proven role of screening for microalbuminuria in patients who do not have diabetes ${ }^{15}$. Patients should not be screened during intercurrent illness or when other factors are present influencing proteinuria (e.g., urinary tract infection, congestive heart failure, acute febrile illness, menstruation or vaginal discharge, exercise within 24 hours, marked hyperglycemia, and high protein diet $)^{1,3,6,15}$. The best possible metabolic control of diabetes should be achieved before investigating patients for microalbuminuria ${ }^{15}$.

ACR is the recommended method for screening microalbuminuria in people with diabetes ${ }^{6,18,32}$. It is a useful surrogate marker for proteinuria and is used instead of the time consuming 24 hour urine collection; 24 hour collections are more burdensome and add little to prediction or accuracy ${ }^{20,33}$. Measurement of ACR in a random urine sample is often found to be easiest method to carry out by patients. But 
there is a diurnal variation in urinary albumin loss, so ACR is best measured on an early morning specimen of urine ${ }^{34}$. Studies have shown that ACR measured in early morning samples correlates closely with 24 hour proteinuria ${ }^{35}$. An early morning sample is also required for the exclusion of orthostatic (postural) proteinuria. Where a first void specimen is not possible, a random urine specimen is acceptable ${ }^{2,15}$. Microalbuminuria can be detected by radioimmunoassay but dipsticks test is usually negative for microalbuminuria ${ }^{36}$. If protein is detectable on a standard urinalysis dipstick, macroalbuminuria ( $>300 \mathrm{mg}$ of urinary albumin per day) is probably already present. Positive dipstick tests should be confirmed in the laboratory by measuring the ACR preferably on an early morning urine sample ${ }^{15}$. In addition to diurnal variation there is also marked day to day variation in urinary albumin excretion. Therefore, it is usual to require multiple positive tests, usually two out of three over a period of months, before microalbuminuria is confirmed. NKF and ADA designates a patient having microalbuminuria when at least two of three urinary collections done in a 3 to 6 month period show elevated levels of albumin ${ }^{1,13}$. Australian guidelines confirm microalbuminuria if at least two of three tests (including the screening test) are positive measured within 3 months. The first abnormal result of spot urine test should be confirmed on an early morning sample ${ }^{3}$. The Australian guidelines recommend a 24 hour urine collection for quantitation of protein excretion if AER or ACR screening is positive for macroalbuminuria ${ }^{3}$.

\section{Treatment of Early Diabetic Kidney Disease}

Interventions initiated at early stage of DKD may postpone or prevent overt nephropathy. Once overt nephropathy is present, progression cannot be halted, only slowed. Treatments that lower urinary albumin excretion slow progression of DKD and improve clinical outcomes. Therefore albuminuria reduction should be considered a treatment target in DKD.

a. Use of angiotensin converting enzyme (ACE) inhibitor or an angiotensin-2 receptor blocker (ARB) drugs: Both ACE inhibitor or an ARB delay progression from micro- to macro-albuminuria in people with DM. A metaanalysis of several trials have shown that ACE inhibitors and ARBs can cause microalbuminuria to regress to no albuminuria in diabetes ${ }^{37,38}$. Systematic review also reveals that there is a reduction in the rate of progression of microalbuminuria to macroalbuminuria in patients with diabetes treated with $\mathrm{ACE}$ inhibitors or $\mathrm{ARBs}^{37-39}$. This effect appeared to be present in patients with or without hypertension, patients with T1DM or T2DM, and patients with or without normal GFR ${ }^{40}$. Various clinical guidelines have recommended treatment with an ACE inhibitors or ARBs in people with diabetes and microalbuminuria even they are normotensive $8,13,26,32,41,42$. ACE inhibitors and ARBs confer both cardioprotective and renoprotective effects. ACE inhibitors and ARBs preferentially lower intra-glomerular pressure and reduce proteinuria. People with T1DM having microalbuminuria should be treated with an ACE inhibitor irrespective of blood pressure $(\mathrm{BP})^{8,26}$. People with T2DM having microalbuminuria should be treated with an ACE inhibitor or an $\mathrm{ARB}$ irrespective of $\mathrm{BP}^{8}$. ACE-inhibitors and ARBs have also been shown to delay progression of nephropathy in those who have macroalbuminuria and renal insufficiency (serum creatinine $>1.5 \mathrm{mg} / \mathrm{dl})^{2}$. Therefore
ACE inhibitors or ARBs should be used in individuals with micro- or macroalbuminuria, titrated to maximum tolerated dose against albumin excretion, aiming for complete normalization ${ }^{2}$.

b. Diabetes control: Hyperglycemia is an independent risk factor for diabetic nephropathy ${ }^{43}$. Studies have shown that the glycosylated hemoglobin (HbA1c) level correlates with loss of renal function and that effective glycemic control prevents the onset and delays the progression of kidney disease in both T1DM and T2DM ${ }^{44-51}$. The Diabetes Control and Complications Trial (DCCT) ${ }^{43}$ conducted in US, and the United Kingdom Prospective Diabetes Study (UKPDS) ${ }^{44}$ have definitively shown that intensive diabetes therapy can significantly reduce the risk of the development of microalbuminuria and overt nephropathy in people with diabetes. Observational studies have reported a faster rate of progression of kidney disease in people with higher HbAlc level ${ }^{47}$. Therefore in diabetes, glycemic control should be optimized to prevent or delay progression of the microvascular complications of diabetes, including DKD.

c. Hypertension control: Elevated BP is strongly associated with the development of albuminuria in people with diabetes. Hypertension control decreases albuminuria, delays nephropathy, and improves survival in both T1DM and $\mathrm{T}_{2} \mathrm{DM}^{52}$. The UKPDS provided strong evidence that control of BP can reduce the development of nephropathy ${ }^{53}$. Studies have shown that in hypertensive patients with DM, ACE inhibitors/ARBs can reduce the level of albuminuria and the rate of progression of renal disease to a greater degree than other antihypertensive agents that lower blood pressure by an equal amount ${ }^{53}$. ACE inhibitors/ARBs have been shown to reduce major cardiovascular outcomes (i.e., myocardial infarction, stroke, death) in patients with diabetes ${ }^{54,55}$, thus further supporting the use of these agents in patients with albuminuria, a cardiovascular risk factor. ACE inhibitors/ ARBs should be used for hypertension in diabetes with microalbuminuria titrated to maximum tolerated dose to control BP. Other drugs, such as diuretics, calcium channel blockers, and $\beta$-blockers, should be used as additional therapy if after 4-6 weeks sufficient blood pressure reduction has not occurred, or as alternate therapy in the rare individual unable to tolerate ACE inhibitors or $\mathrm{ARBs}^{6}$.

When ACE-inhibitor/ARB therapy is started, some patients with CKD may have an initial decrease in GFR (usually less than $10 \mathrm{~mL}$ per minute per $1.73 \mathrm{~m} 2$ ), a mild increase in the serum creatinine concentration (less than 20 percent of the baseline value), and a mild increase in the potassium level (usually less than $0.5 \mathrm{mmol}$ per $\mathrm{L})^{56}$. Therefore, in people with CKD, serum creatinine and potassium levels should be measured and the GFR should be estimated before starting ACE inhibitor/ARB therapy. These measurements should be repeated between 1 and 2 weeks after starting ACE inhibitor/ARB therapy and after each dose increase ${ }^{18}$. ACE inhibitor/ARB therapy should not normally be started if the pretreatment serum potassium concentration is significantly above the normal reference range (typically more than 5.0 $\mathrm{mmol} / \mathrm{L})^{18}$.

d. Limitation of protein intake: The effect of dietary protein restriction on kidney disease is the subject of debate. Some studies in patients with varying stages of DKD have shown that dietary protein restriction helps slow the progression 
of albuminuria, GFR decline, and occurrence of ESRD ${ }^{57-61}$. However, the MDRD study and other several small trials were unable to demonstrate a robust benefit in delaying progression to advanced stages of CKD with dietary restriction of protein intake $\mathrm{e}^{57,62-65}$. Nonetheless, restriction of dietary protein intake has been recommended for CKD patients. ADA recommends reduction of protein intake to $0.8-1.0 \mathrm{~g} / \mathrm{kg}$ body weight $/$ day in individuals with diabetes and the earlier stages of CKD and to $0.8 \mathrm{~g} / \mathrm{kg}$ body weight/day in the later stages of CKD that may improve renal function ${ }^{6}$. Scottish guidelines do not recommend protein restrictions in patients with early stages of chronic kidney disease (stages $1-3)^{8}$. NKF targets dietary protein intake $0.8 \mathrm{~g} / \mathrm{kg}$ body weight per day for people with diabetes and CKD stages $1-4^{13}$. Diets for people with diabetes have traditionally been $15 \%$ to $20 \%$ protein $^{66}$. People with diabetes and CKD should avoid high-protein diets $(\geq 20 \%$ of total daily calories) ${ }^{13}$. IDF guidelines advise limiting protein intake to $1 \mathrm{~g} / \mathrm{kg}$ daily if proteinuric ${ }^{2}$. Protein restriction is not advisable in those with cachexia or low serum albumin.

\section{e. Other interventions:}

(i) Smoking is a strong risk factor for cardiovascular mortality in patients at risk for $\mathrm{CKD}^{67}$. Several lines of evidence have shown that smoking increases the risk and progression of diabetic nephropathy ${ }^{67-69}$. The results of one small study showed that smoking cessation reduced the progression of kidney disease by 30 percent in patients with T1DM ${ }^{70}$. People with DM should be informed that smoking increases the risk of CKD and cardiovascular disease, an individuals smoking cessation is an important recommendation irrespective of CKD.

(ii) Microalbuminuria is a well-established marker of increased cardiovascular risk ${ }^{2,7}$. ADA recommends aspirin therapy (75-162 $\mathrm{mg} /$ day) as a primary prevention strategy in those with diabetes at increased CVD risk which also includes most men $>50$ years of age or women $>60$ years of age who have albuminuria ${ }^{6}$.

(iii) Dyslipidemia may contribute to the development and progression of DKD by causing intrarenal arteriosclerosis or direct toxicity to renal cells ${ }^{71,72}$. A recent meta-analysis of 13 small studies showed that lipid reduction preserves GFR and reduces proteinuria ${ }^{73}$. Given the strong association between dyslipidemia and cardiovascular disease, management of blood lipid in DM is recommended irrespective of the presence of indicators of $\mathrm{CKD}$. NKF recommends using LDL-C lowering medicines, such as statins or statin/ezetimibe combination, to reduce risk of major atherosclerotic events in patients with diabetes and $\mathrm{CKD}^{41}$. Target LDL-C in people with diabetes and CKD stages $1-4$ should be $<100 \mathrm{mg} / \mathrm{dL}$; and $<70 \mathrm{mg} / \mathrm{dL}$ is a therapeutic option for diabetic patients with $\mathrm{CVD}^{13}$. NICE guidelines offer statins to people with CKD for the secondary prevention of CVD irrespective of baseline lipid values ${ }^{18}$.

(iv) Exercise and weight loss may reduce proteinuria ${ }^{36}$.

\section{Key Recommendations}

Microalbuminuria is the earliest, clinically detectable manifestation of classic DKD. Persistent microalbuminuria in diabetes has been associated with progression to overt nephropathy and ultimately to ESRD; and is an increased risk of atherosclerosis with cardiovascular morbidity and mortality. Proteinuria reduction should be a treatment target regardless of baseline urinary protein excretion ${ }^{2}$. Therefore there is general agreement that people with diabetes should be screened regularly to detect early markers of kidney damage and receive treatment ${ }^{2}$. The key recommendations can be summarized as follows:

a. Kidney function should be assessed at diagnosis and annually thereafter by (a) urine test for albuminuria and (b) measurement of serum creatinine and calculation of eGFR ${ }^{2}$. ADA recommends yearly screening for microalbuminuria in (a) type 1 diabetic patients who have had diabetes $>5$ years and (b) all type 2 diabetic patients starting at diagnosis ${ }^{1}$.

b. The ACR is the preferred method of detecting albuminuria in diabetes ${ }^{6,8,18,32}$. ACR should be measured using a morning urine sample because studies have shown that it correlates best with 24 hour protein excretion ${ }^{18,32}$.

c. ACE inhibitors and ARBs are effective at reducing proteinuria, slowing the decline in GFR and retarding the progression of kidney disease. Therefore all the guidelines recommend treatment initiation with ACE inhibitors or ARBs unless contraindicated in diabetes having persistent microalbuminuria (incipient nephropathy) or macroalbuminuria (overt diabetic nephropathy) independently of the presence of hypertension ${ }^{1-3,6,13,18,36,41}$. People with T1DM and microalbuminuria should be treated with an $\mathrm{ACE}$ inhibitor irrespective of $\mathrm{BP}^{8}$. People with T2DM and microalbuminuria should be treated with an ACE inhibitor or an $\mathrm{ARB}$ irrespective of $\mathrm{BP}^{8}$.

d. To reduce the risk and/or slow the progression of nephropathy, effective glycemic control should be maintained in diabetes ${ }^{1,2,6,8}$. ADA \& Canadian guidelines recommends that plasma values for preprandial glucose be kept in the 5.0$7.2 \mathrm{mmol} / \mathrm{L}(90-130 \mathrm{mg} / \mathrm{dL})$ range and HbAlc should be < $7 \%$ to prevent progression of CKD in patients with $\mathrm{DM}^{32,55}$.

NKF and Australian guidelines recommend a target $\mathrm{HbA1c}$ of $7.0 \%$ to prevent or delay progression of the microvascular complications of diabetes, including $\mathrm{DKD}^{3,41}$.

e. To reduce the risk and/or slow the progression of nephropathy, BP control should be optimized ${ }^{1,2,6}$. An ACE inhibitor or $\mathrm{ARB}$ is recommended as antihypertensive for all diabetic patients with microalbuminuria having hypertension ${ }^{1,3,8}$. According to various clinical guidelines, the primary goal of therapy for nonpregnant diabetic patients $\geq 18$ years of age is to decrease BP to and maintain it at $<130$ $\mathrm{mmHg}$ systolic and $<80 \mathrm{mmHg}$ diastolic ${ }^{1-3,6,8,17,18}$. For those with microalbuminuria the target is $130 / 80 \mathrm{~mm} \mathrm{Hg}$. It has been suggested that those with total proteinuria $>1 \mathrm{~g} /$ day the target should be $125 / 75 \mathrm{~mm} \mathrm{Hg}^{74}$.

f. When ACE inhibitors or ARBs are used, serum creatinine and potassium levels need to be monitored ${ }^{1,2,6}$.

$\mathrm{DKD}$ is now the leading cause of CKD requiring renal replacement therapy in many parts of the world, and its prevalence is increasing disproportionately in the developing world. The onset and course of DKD can be ameliorated to a very significant degree by several interventions, but these interventions have their greatest impact if initiated at a point very early in the course of the development of this 
complication. The benefits of a multifactorial intervention approach in the management of people with diabetes and microalbuminuria have been clearly demonstrated ${ }^{75,76}$. Interventions initiated at the stage of microalbuminuria may postpone or prevent overt nephropathy. Therefore people with diabetes and microalbuminuria should be treated with a multifactorial intervention approach that includes improved glycemic control, BP control, lipid lowering, aspirin use, smoking cessation, exercise programs and dietary intervention to reduce the development of overt nephropathy, ESRD and death

\section{References}

1. American Diabetes Association Position Statement: Diabetic Nephropathy. Diabetes Care. 2003;26:S94-S98.

2. International Diabetes Federation, 2012 Clinical Guidelines Task Force Global Guideline for Type 2 Diabetes. Available from: http://www.societatediabet.ro/pdf/Global-Guideline-for-Type-2-DiabetesIDF-2012.pdf

3. Chadban S, Howell M, Twigg S, Thomas M, Jerums G, Alan C, et al. National Evidence Based Guideline for Diagnosis, Prevention and Management of Chronic Kidney Disease in Type 2 Diabetes. Diabetes Australia and the NHMRC, Canberra 2009.

4. Zimmet PZ, Alberti KG, Shaw J. Global and societal implications of the diabetes epidemic. Nature. 2001;414:782-787.

5. United States Renal Data System. 2000 Annual data report. Bethesda MD.: National Institutes of Health, National Institute of Diabetes and Digestive and Kidney Diseases, June 2003.

6. American Diabetes Association. Standards of medical care in diabetes. Diabetes Care. 2013;36:S11-S66.

7. Garg JP, Bakris GL. Microalbuminuria: marker of vascular dysfunction, risk factor for cardiovascular disease. Vasc Med. 2002;7:35-43.

8. Scottish Intercollegiate Guidelines Network. Management of diabetes. A national clinical guideline. 2010 March. Available from http://www.sign.ac.uk/pdf/ sign116.pdf

9. Cumming A. The renal system. In Doglas G, Nicol F, \& Robertson C. Macleod's Clinical Examination. $11^{\text {th }}$ International ed. Churchill Livingstone Elsevier. $2005 ; 193$.

10. Klausen K, Borch-Johnsen K, Feldt-Rasmussen B, Jensen G, Clausen P, Scharling H, et al. Very low levels of microalbuminuria are associated with increased risk of coronary heart disease and death independently of renal function, hypertension, and diabetes. Circulation. 2004; 110:32-35.

11. Deferrari G, Repetto M, Calvi C, Ciabattoni M, Rossi C, Robaudo C: Diabetic nephropathy: from micro- to macroalbuminuria. Nephrol Dial Transplant. 1998;13:11-15.

12. Gall MA, Hougaard P, Borch-Johnsen K, Parving HH.
Risk factors for development of incipient and overt diabetic nephropathy in patients with non-insulin dependent diabetes mellitus: prospective, observational study. BMJ. 1997;314:783-788.

13. National Kidney Foundation. K/DOQI Clinical Practice Guidelines and Clinical Practice Recommendations for Diabetes and Chronic Kidney Disease. Am J Kidney Dis. 2007;49(2 suppl 2):S1-179.

Available from http://www.kidney.org/professionals/ KDOQI/guideline_diabetes/

14. Alsaad KO, Herzenberg AM. Distinguishing diabetic nephropathy from other causes of glomerulosclerosis: an update. J Clin Pathol. 2007;60:18-26.

15. The Renal Association. Chronic kidney disease in adults UK guidelines for identification, management and referral. March 2006. Available from:

h t t p : / / w w w.ren a l.org/CKDguide/full/ CKDprintedfullguide.pdf

16. The National Collaborating Centre for Chronic Conditions. Type 2 diabetes: the management of type 2 diabetes. NICE clinical guideline 87. London: Royal College of Physicians; 2009.

Available from http://www.nice.org.uk/nicemedia/pdf/ CG87NICEGuideline.pdf

17. Canadian Diabetes Association Clinical Practice Guidelines Expert Committee. Canadian Diabetes Association 2008 clinical practice guidelines for the prevention and management of diabetes in Canada. Can J Diabetes. 2008;32:S95-S98. Available from http:// www.diabetes.ca

18. NICE clinical guidelines. CG73 Chronic kidney disease. Early identification and management of chronic kidney disease in adults in primary and secondary care. September 2008. Available from http://publications. nice.org.uk/chronic-kidney-disease-cg73

19. National Kidney Foundation. K/DOQI clinical practice guidelines for chronic kidney disease: evaluation, classification, and stratification. Am J Kidney Dis. 2002;39:S1-266.

20. Levey AS, Coresh J, Balk E, Kausz AT, Levin A, Steffes MW et al. National Kidney Foundation Practice Guidelines for Chronic Kidney Disease: Evaluation, Classification, and Stratification. Ann Intern Med. 2003; 139:137-147.

21. Levey AS, Bosch JP, Lewis JB, Greene T, Rogers N, Roth D. A more accurate method to estimate glomerular filtration rate from serum creatinine: a new prediction equation. Modification of Diet in Renal Disease Study Group. Ann Intern Med. 1999;130:461-70.

22. Rigalleau V, Lasseur C, Perlemoine C, Barthe N, Raffaitin C, Liu C, et al. Estimation of glomerular filtration rate in diabetic subjects: Cockcroft formula or Modification of Diet in Renal Disease study equation? Diabetes Care. 2005;28:838-843. 
23. Davies DF, Shock NW. Age changes in glomerular filtration rate, effective renal plasma flow, and tubular excretory capacity in adult males. $\mathrm{J}$ Clin Invest. 1950;29:496-507.

24. Lindeman RD, Tobin J, Shock NW. Longitudinal studies on the rate of decline in renal function with age. J Am Geriatr Soc. 1985;33:278-85.

25. Rowe JW, Andres R, Tobin JD, Norris AH, Shock NW. The effect of age on creatinine clearance in men: a cross-sectional and longitudinal study. J Gerontol. 1976;31:155-63.

26. American Diabetes Association: Position statement: Diabetic nephropathy. Diabetes Care. 1999;22 (Suppl 1):S66-69.

27. Kramer HJ, Nguyen QD, Curhan G, Hsu CY. Renal insufficiency in the absence of albuminuria and retinopathy among adults with type 2 diabetes mellitus. JAMA 2003;289:3273-3277.

28. Garg AX, Kiberd BA, Clark WF, Haynes RB, Clase CM. Albuminuria and renal insufficiency prevalence guides population screening: results from the NHANES III. Kidney Int. 2002;61:2165-75.

29. Caramori ML, Fioretto P, Mauer M. Low glomerular filtration rate in normoalbuminuric type 1 diabetic patients: an indicator of more advanced glomerular lesions. Diabetes 2003;52:1036-40.

30. Bash LD, Selvin E, Steffes M, Coresh J, Astor BC. Poor Glycemic Control in Diabetes and the Risk of Incident Chronic Kidney Disease Even in the Absence of Albuminuria and Retinopathy: Atherosclerosis Risk in Communities (ARIC) Study. Archives of Internal Medicine. 2008;168:2440-2447.

31. Kramer, H \& Molitch, ME. Screening for Kidney Disease in Adults with Diabetes. Diabetes Care. 2005;28:18131816.

32. Levin A, Hemmelgarn B, Culleton B, Tobe S, McFarlane P, Ruzicka M, et al. Guidelines for the management of chronic kidney disease. CMAJ. 2008;179:1154-62.

33. Eknoyan G, Hostetter T, Bakris GL, et al. Proteinuria and other markers of chronic kidney disease: a position statement of the National Kidney Foundation (NKF) and the National Institute of Diabetes and Digestive and Kidney Diseases (NIDDK). Am J Kidney Dis. 2003;42:617-622.

34. Mogensen CE, Keane WF, Bennett PH, Jerums G, Parving HH, Passa P, et al. Prevention of diabetic renal disease with special reference to microalbuminuria. Lancet 1995;346:1080-4.

35. Ginsberg JM, Chang BS, Matarese RA, Garella S. Use of single voided urine samples to estimate quantitative proteinuria. N Engl J Med. 1983;309:1543-6.

36. Goddard J, Turner AN, Stewart LH. Kidney and urinary tract disease. In: Colledge NR, Walker BR S \& Ralston SH. Davidson's Principle and Practice of Medicine. $21^{\text {st }}$ International ed. Churchill Livingstone Elsevier;2010:480-496.
37. The ACE Inhibitors in Diabetic Nephropathy Trialist Group. Should all patients with type 1 diabetes mellitus and microalbuminuria receive angiotensin-converting enzyme inhibitors: a meta-analysis of individual patient data. Ann Intern Med. 2001;134:370-379.

38. Strippoli GFM, Bonifati C, Craig M, Navaneethan SD, Craig JC. Angiotensin converting enzyme inhibitors and angiotensin II receptor antagonists for preventing the progression of diabetic kidney disease (Cochrane Review). In: The Cochrane Library, Issue 4, 2006. London: Wiley

39. Kshirsagar AV, Joy MS, Hogan SL, Falk RJ, Colindres RE. Effect of ACE inhibitors in diabetic and nondiabetic chronic renal disease: a systematic overview of randomized placebo-controlled trials. Am J Kidney Dis. 2000;35:695-707.

40. Strippoli GFM, Craig M, Craig JC. Antihypertensive agents for preventing diabetic kidney disease (Cochrane Review). In: The Cochrane Library, Issue 4, 2006. London: Wiley

41. National Kidney Foundation. KDOQI Clinical Practice Guideline for Diabetes and CKD: 2012 update. Am J Kidney Dis. 2012;60:850-886.

42. Parving HH, Lehnert H, Brochner-Mortensen J, Gomis $\mathrm{R}$ et al. The effect of irbesartan on the development of diabetic nephropathy in patients with type 2 diabetes. $\mathrm{N}$ Engl J Med. 2001;345:870-8.

43. Diabetes Control and Complications Trial Research Group: The effect of intensive treatment of diabetes on the development and progression of long-term complications in insulin-dependent diabetes mellitus. N Engl J Med. 1993;329:977-986.

44. UK Prospective Diabetes Study Group: Intensive blood glucose control with sulphonylureas or insulin compared with conventional treatment and risk of complications in patients with type 2 diabetes (UKPDS 33). Lancet. 1998;352:837-853.

45. The Action to Control Cardiovascular Risk in Diabetes Study Group. Effects of intensive glucose lowering in type 2 diabetes. N Engl J Med. 2008; 358:2545-2559.

46. The ADVANCE Collaborative Group. Intensive blood glucose control and vascular outcomes in patients with type 2 diabetes. N Engl J Med. 2008;358:2560-2572.

47. Mulec H, Blohme G, Grande B, Bjorck S. The effect of metabolic control on rate of decline in renal function in insulin-dependent diabetes mellitus with overt diabetic nephropathy. Nephrol Dial Transplant. 1998;13:651-5.

48. Reichard P, Nilsson BY, Rosenqvist U. The effect of longterm intensified insulin treatment on the development of microvascular complications of diabetes mellitus. $\mathrm{N}$ Engl J Med 1993;329:304-309.

49. Ismail-Beigi F, Craven T, Banerji MA, Basile J, Calles J, Cohen RM, et al. ACCORD Trial Group. Effect of intensive treatment of hyperglycaemia on microvascular outcomes in type 2 diabetes: an analysis of the ACCORD randomised trial. Lancet. 2010;376:419-430. 
50. Di Landro D, Catalano C, Lambertini D, Bordin V, Fabbian F, Naso A, Romagnoli G: The effect of metabolic control on development and progression of diabetic nephropathy. Nephrol Dial Transplant. 1998;13:35-43.

51. Molitch M: The relationship between glucose control and the development of diabetic nephropathy in type I diabetes. Sem Nephrol. 1997;17:101-13.

52. Parving $\mathrm{H}$. Is antihypertensive treatment the same for NIDDM and IDDM patients? Diabetes Res Clin Pract. 1998;39:S43-47.

53. UK Prospective Diabetes Study Group. Tight blood pressure control and risk of macrovascular and microvascular complications in type 2 diabetes: UKPDS 38. BMJ. 1998;317:703-713.

54. Heart Outcomes Prevention Evaluation Study Investigators. Effects of ramipril on cardiovascular and microvascular outcomes in people with diabetes mellitus: results of the HOPE study and MICRO-HOPE substudy. Lancet. 2000;355:253-259.

55. American Diabetes Association. Standards of medical care for patients with diabetes mellitus. Diabetes Care. 2003;26:S33-50.

56. Levey AS. Clinical practice. Nondiabetic kidney disease. N Engl J Med. 2002;347:1505-1511.

57. Hansen HP, Tauber-Lassen E, Jensen BR, Parving HH. Effect of dietary protein restriction on prognosis in patients with diabetic nephropathy. Kidney Int. 2002;62:220-228.

58. Kasiske BL, Lakatua JD, Ma JZ, Louis TA. A metaanalysis of the effects of dietary protein restriction on the rate of decline in renal function. Am J Kidney Dis. 1998;31:954-961.

59. Fouque D, Wang P, Laville M, Boissel JP. Low protein diets for chronic kidney disease in non diabetic adults (Cochrane Review).In: The Cochrane Library, Issue 4, 2000. London: Wiley

60. Robertson L, Waugh N, Robertson A. Protein restriction for diabetic renal disease (Cochrane Review). In: The Cochrane Library, Issue 4, 2007. London: Wiley

61. Pedrini MT, Levey AS, Lau J, Chalmers TC, Wang $\mathrm{PH}$. The effect of dietary protein restriction on the progression of diabetic and nondiabetic renal diseases: a meta-analysis. Ann Intern Med. 1996;124:627-32.

62. Klahr S, Levey AS, Beck GJ, Caggiula AW, Hunsicker L, Kusek JW, et al. The effects of dietary protein restriction and blood-pressure control on the progression of chronic renal disease. Modification of Diet in Renal Disease Study Group. N Engl J Med. 1994;330:877-84.

63. Meloni C, Morosetti M, Suraci C, Pennafina MG, Tozzo $\mathrm{C}$, Taccone-Gallucci $\mathrm{M}$, et al. Severe dietary protein restriction in overt diabetic nephropathy: benefits or risks? J Ren Nutr. 2002;12:96-101.

64. Meloni C, Tatangelo P, Cipriani S, Rossi V, Suraci C, Tozzo C, et al. Adequate protein dietary restriction in diabetic and nondiabetic patients with chronic renal failure. J Ren Nutr. 2004;14:208-13.

65. Pijls LTJ, de Vries H, van Eijk J, Donker AJM. Protein restriction, glomerular filtration rate and albuminuria in patients with type 2 diabetes mellitus: A randomized trial. Eur J Clin Nutr. 2002;56:1200-7.

66. Evidence-based nutrition principles and recommendations for the treatment and prevention of diabetes and related complications. Diabetes Care. 2002;225:202-212.

67. Orth SR, Stockmann A, Conradt C, Ritz E, Ferro M, Kreusser W, et al. Smoking as a risk factor for end-stage renal failure in men with primary renal disease. Kidney Int. 1998;54:926-31.

68. Marcantoni C, Ortalda V, Lupo A, Maschio G: Progression of renal failure in diabetic nephropathy. Nephrol Dial Transplant. 1998;13:16-19.

69. Ritz E: Nephropathy in type 2 diabetes. J Intern Med. 1999;245:111-26.

70. Sawicki PT, Didjurgeit U, Muhlhauser I, Bender R, Heinemann L, Berger M. Smoking is associated with progression of diabetic nephropathy. Diabetes Care. 1994; 17:126-31.

71. Keane WF. The role of lipids in renal disease: future challenges. Kidney Int. 2000;75:S27-31.

72. Kasiske BL, O'Donnell MP, Kim Y, Keane WF. Treatment of hyperlipidemia in chronic progressive renal disease. Curr Opin Nephrol Hypertens. 1993;2:602-8.

73. Fried LF, Orchard TJ, Kasiske BL. Effect of lipid reduction on the progression of renal disease: a metaanalysis. Kidney Int. 2001;59:260-9.

74. Williams B, Poulter NR, Brown MJ, Davis M et al. Guidelines for management of hypertension: report of the fourth working party of the British Hypertension Society, 2004-BHS IV. J Hum Hypertens. 2004; 18:13985.

75. Gaede P, Vedel P, Parving HH, Pedersen O. Intensified multifactorial intervention in patients with type 2 diabetes mellitus and microalbuminuria: the Steno type 2 randomised study. Lancet.1999;353:617-622.

76. Gaede P, Lund-Andersen H, Parving HH, Pedersen O. Effect of a multifactorial intervention on mortality in type 2 diabetes. N Engl J Med. 2008;358:580-591. 